\title{
Roscovitine has anti-proliferative and pro-apoptotic effects on glioblastoma cell lines: A pilot study
}

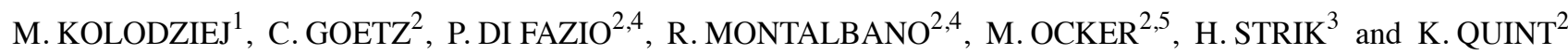 \\ ${ }^{1}$ Department of Neurosurgery, University Hospital Giessen, Giessen; ${ }^{2}$ Institute for Surgical Research, \\ University of Marburg, Marburg; Departments of ${ }^{3}$ Neurology and ${ }^{4}$ Visceral, \\ Thoracic and Vascular Surgery, University Hospital Marburg, Marburg, Germany
}

Received March 30, 2015; Accepted June 3, 2015

DOI: $10.3892 /$ or.2015.4105

\begin{abstract}
Purine analogue roscovitine, a cyclin-dependent kinase (CDK) inhibitor, has shown strong anti-proliferative and pro-apoptotic effects in solid and hematologic cancers such as non small-cell lung cancer and lymphomas. It targets CDK2, 7 and 9 preferentially, which are also overexpressed in glioblastoma. Therefore, the biological effects of roscovitine in glioblastoma cell lines were investigated. Glioblastoma A172 and G28 cell lines were incubated with serial concentrations of roscovitine for 24-120 h. Proliferation was measured using the xCELLigence Real-Time Cell Analyzer, an impedance-based cell viability system. Cell cycle distribution was assessed by flow cytometry and gene expression was quantified by quantitative RT-PCR and western blot analysis. Roscovitine exhibited a clear dose-dependent anti-proliferative and pro-apoptotic effect in the A172 cell line, while $\mathrm{G} 28$ cells showed a anti-proliferative effect only at $100 \mu \mathrm{M}$. The results of the flow cytometric (FACS) analysis revealed a dose-dependent increase of the G2/M and sub-G1 fractions in A172 cells, while G28 cells responded with an elevated sub-G1 fraction only at the highest concentration. Roscovitine led to a dose-dependent decrease of transcripts of p53, CDK 7 and cyclins $A$ and $E$ and an increase of $>4$-fold of p21 in A172 cells. In G28 cells, a dose-dependent induction of CDK2, p21 and cyclin D was observed between 10 and $50 \mu \mathrm{M}$ roscovitine after $72 \mathrm{~h}$, however, at the highest concen-
\end{abstract}

Correspondence to: Dr Malgorzata Kolodziej, Department of Neurosurgery, University Hospital Giessen, Klinikstrasse 33, D-35392 Giessen, Germany

E-mail: malgorzata.kolodziej@neuro.med.uni-giessen.de

Present address: ${ }^{5}$ Experimental Medicine Oncology, Bayer Pharma AG, Berlin, Germany

Abbreviations: ALL, acute lymphatic leukemia; CAK, CDK activating kinase; $\mathrm{CDK}$, cyclin-dependent kinase; $\mathrm{CNS}$, central nervous system; CTD, c-terminal-domain; DMSO, dimethyl sulfoxide; FACS, flow cytometry; FBS, fetal bovine serum; GBM, glioblastoma; RLF, replication licensing factor; RTCA, real-time cell analyzer

Key words: glioblastoma multiforme, cyclin-dependent kinases, DNA synthesis, roscovitine, proliferation rate tration of $100 \mu \mathrm{M}$, all investigated genes were downregulated. Roscovitine exerted clear dose-dependent anti-proliferative and pro-apoptotic effects in A172 cells and less distinct effects on $\mathrm{G} 28$ cells. In A172 cells, roscovitine led to G2/M arrest and induced apoptosis, an effect accompanied by induced p21 and a reduced expression of CDK2, 7 and 9 and cyclins A and $\mathrm{E}$. These effects requre further studies on a larger scale to confirm whether roscovitine can be used as a therapeutic agent against glioblastoma.

\section{Introduction}

Glioblastoma multiforme (GBM) is common and is an aggressive brain tumor in adults. Despite the introduction of radiation therapy and chemotherapy with temozolomide in addition to surgery, general survival has been increased from 12 to 14 months only $(1,2)$. Specific genetic changes have been classified and related to characteristic molecular pathways involved in the control of tumor development. With an increasing understanding of the molecular behaviour of tumors, specifically of GBM, variations in pharmacogenomic profiles in combination with radiation therapy potentially improve the outcome of therapy in this lethal disease. Schiffer et al reported that in glioblastoma, the highest quantity of apoptosis was detected in the area with the highest mitotic rate suggesting that, during mitosis, some glioblastomas are exposed to cell death (3).

Uncommon regulation of cyclins, cyclin-dependent kinases (CDKs) and endogenous CDK inhibitors has been described in gliomas, demonstrating that CDK modulators may be important for treatment of GBM (4-9). Roscovitine, a CDK modulator is a potent and selective small molecule inhibitor of the cyclin-dependent kinases CDK2/cyclin B, CDK2/cyclin A, CDK2/cyclin E and CDK5, and leads to induction of p53 $(10,11)$. Furthermore, roscovitine inhibits the growth of several human cancer cell lines including breast, ovarian, pancreatic, colon, renal, hepatocellular, pituitary carcinoma and neuroblastoma (12-18). Roscovitine has been found to inhibit different solid and hematological tumor cell lines including acute lymphoblastic leukemia (ALL), which occurs frequently in children and is correlated with the central nervous system (CNS) $(19,20)$. The drug inhibits the G1/S and $\mathrm{G} 2 / \mathrm{M}$ transition in a concentration dependent manner. 
Other studies reported an inhibition of the DNA synthesis in the cerebral cortex, an effect that appears to be independent from its ability to inhibit CDKs or the replication licensing factor (RLF) $(10,11,21)$. The concentration and half-life of roscovitine are almost similar in plasma and in brain tissues. Roscovitine is metabolized in humans mainly by CYP3A4 and CYP2B6 enzymes, and its elimination is rapid via the bile within the first $24 \mathrm{~h}(22,23)$. Most chemotherapeutic agents do not cross the blood-brain barrier and do not reach the CNS in adequate concentrations to eliminate tumor cells, while roscovitine is highly distributed over the blood-brain barrier (24). Roscovitine is a potential inhibitor of CDK5, which has a significant function in the developing brain, such as neuronal migration (23). A functional p53 protein level was suggested as an efficient enhancer in roscovitine-induced apoptosis in cancer. Roscovitine-induced apoptosis was shown to be p53-dependent in MCF-7 cells, whereas roscovitine may induce apoptosis in B-CLL cells, irrespective of the functional status of the p53 pathway, and may be considered a therapeutic agent able to improve the outcome of B-CLL-resistant tumors. Therefore, the possible relationship between roscovitine and p53 regulation remains to be elucidated (25-27). Furthermore, roscovitine decreased production of the cell cycle inhibitor p21 and induced apoptosis. This effect was observed as the most efficient in cell lines expressing p53 protein with a full activity. The cells expressing partially and conditionally active p53wt mutants responded to roscovitine less efficiently. This observation suggests that patients with tumors exhibiting p53 can benefit from roscovitine therapy (28).

In the present study, we investigated the effects of roscovitine on proliferation, apoptosis and cell cycle regulation in glioblastoma cell cultures. Due to selective inhibition of CDKs by roscovitine, particularly CDK1, 2, 5, 7 and 9, which are involved in the cell cycle regulation, we assessed the interaction between roscovitine and CDKs. Furthermore, we investigated CDK binding partners including cyclin A, D and $\mathrm{E}$ and tumor-suppressor proteins p21 and p53. The results identified the influence of roscovitine in apoptosis in glioblastoma cell line as a promising therapeutic agent.

\section{Materials and methods}

Cell culture. The A172 and NCE-G28 cell lines were obtained from the American Type Culture Collection (ATCC, Manassas, VA, USA). The two cell lines were routinely cultured in plastic flasks $\left(75 \mathrm{~cm}^{2}\right)$ or 6-well-plates in Dulbecco's modified Eagle's medium (DMEM; Biochrom GmbH, Berlin, Germany) supplemented with $10 \%$ fetal bovine serum (FBS; Biochrom) and $1 \mathrm{ppm}$ antibiotics (penicillin and streptomycin; Biochrom). The cells were incubated at $37^{\circ} \mathrm{C}$, under $95 \%$ humidity and $5 \%$ $\mathrm{CO}_{2}$ saturation. At 70-80\% confluence, the cells were passaged by being washed with PBS and trypsinized with trypsin/EDTA (both from Biochrom) for 3-7 min. PBS and trypsin/EDTA were preheated at $37^{\circ} \mathrm{C}$ in a water bath. The procedures were performed under sterile conditions in a laminar flow cabinet.

Drugs and treatments. Roscovitine was prepared as a $1 \mathrm{M}$ stock solution in dimethyl sulfoxide (DMSO; Sigma Aldrich, Hamburg, Germany). Stock solution was diluted in culture medium in order to obtain the final concentrations of $1,10,25$,
50 and $100 \mu \mathrm{M}$ for the cell treatment. Aliquots of the roscovitine stock and the final concentrations were stored until use at $-20^{\circ} \mathrm{C}$. The cells were treated with roscovitine $24 \mathrm{~h}$ after seeding to guarantee adherence. In the presence of the drug, the cells were incubated for 24-96 h. Controls were treated with complete medium as described above while omitting the drug.

$x$ CELLigence. Impedance-based measurement of cell proliferation and $\mathrm{IC}_{50}$ were performed with the $\mathrm{xCELLigence}$ Real-Time Cell Analyzer (RTCA) in 96-well plates (E-plates) (all from Roche Applied Science, Penzberg, Germany) under standard culture conditions as described above. The readout recorded by the RTCA is a dimensionless cell index $(\mathrm{CI})$ value that correlates with cell number. The setup of the experiment and recording of data included background measurement with $100 \mu \mathrm{l}$ of cell-free medium, followed by the addition of a drug-free cell suspension $\left(10^{4}\right.$ cells $/ 50 \mu \mathrm{l} /$ well $)$. The cells were continuously measured every $15 \mathrm{~min}$ and allowed to adhere and proliferate for $24 \mathrm{~h}$ in drug-free medium. For the treatment, the medium was completely replaced with roscovitine-containing medium in serial concentrations of $1,10,25,50$ and $100 \mu \mathrm{M}$ or drug-free DMSO-containing medium for the controls. Readings were performed for at least $96 \mathrm{~h}$ after the treatment. Experiments were performed in FBS-deficient-medium $(0.125 \%$ FBS $)$ to assess the drug response under starvation. The samples were analyzed at least in triplicate.

The RTCA-software version 1.2.2 was used to analyze the data. Curves were normalized to the time-point just prior to adding the drug, to which a CI of 1 was assigned.

Flow cytometry (FACS). Cell cycle analysis was performed using flow cytometry. Cells were seeded in triplicates in 6 -well plates $\left(3 \times 10^{5} /\right.$ well) and allowed to attach for $24 \mathrm{~h}$. Subsequently, the cells were treated with roscovitine at the final concentrations of $10,25,50$ and $100 \mu \mathrm{M}$. After an additional incubation period of 24-96 h, the cells were washed with PBS (Biochrom) and collected by standard trypsinization. The collected medium, the PBS and the cell-trypsin suspension were centrifuged for $10 \mathrm{~min}$ at $1,000 \mathrm{rpm}$. Cell pellets were resuspended with propidium iodide (PI; Sigma Aldrich) at a ratio of $10^{5}$ cells $/ \mathrm{ml}$ and incubated for $60 \mathrm{~min}$ on ice in the dark. Analysis was immediately performed. For the evaluation of the assays and the data, the BD FACSCalibur flow cytometer and the corresponding CellQuest ${ }^{\mathrm{TM}}$ Pro Software (BD Biosciences, San Jose, CA, USA) were used.

RNA isolation, cDNA synthesis and real-time-quantitative PCR (RT-qPCR). Cells were collected using standard trypsinization as described above and lysed using QIAzol Lysis reagent (Qiagen, Hilden, Germany), followed by RNA isolation with the RNeasy Mini kit (Qiagen), as per the manufacturer's instructions. RNA concentration was measured photometrically using the NanoDrop ND-1000 Sprectrophotometer (Thermo Fisher Scientific, Wilmington, DE, USA). Five-hundred nanograms of total RNA were used for cDNA reverse transcription by using the iScript ${ }^{\mathrm{TM}}$ cDNA synthesis kit (Bio-Rad Laboratories $\mathrm{GmbH}$, Munich, Germany). RT-qPCR was performed using the SsoFast EvaGreen Supermix kit (Bio-Rad) and the primers: CDK2 (cat. no. QT00005586), CDK7 (QT00028700), CDK9 (QT00208523), cyclin A (QT00014798), cyclin D 


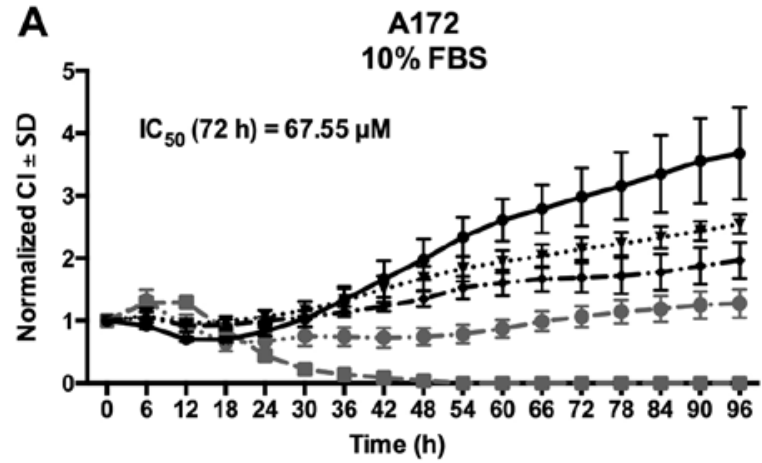

C

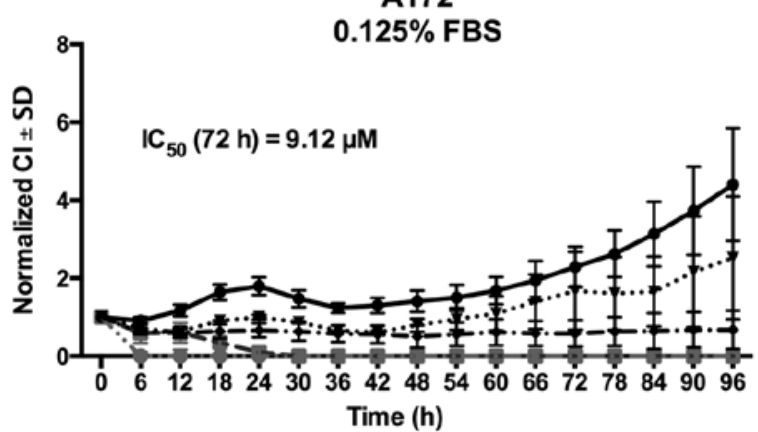

B

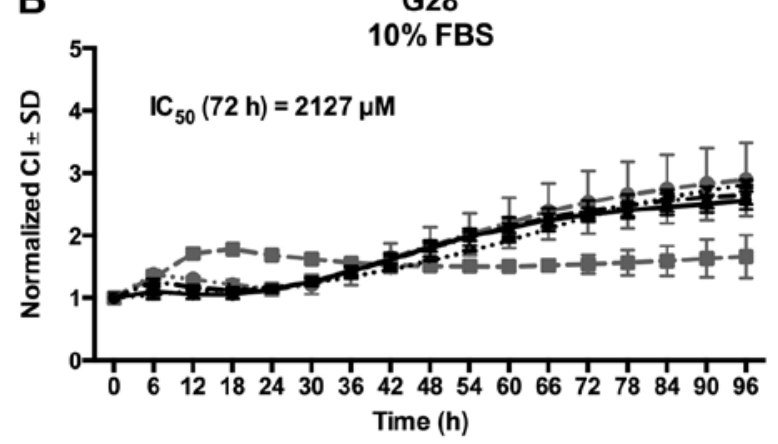

D

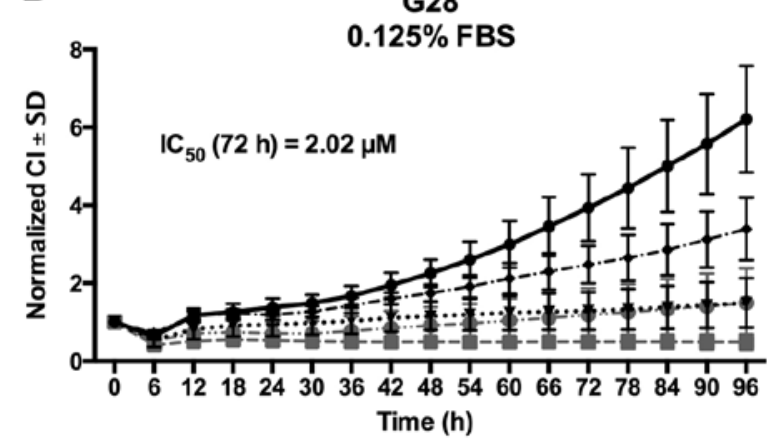

Time (h)

$$
\text { Control } \text {... } 10 \mu \mathrm{M} \rightarrow 25 \mu \mathrm{M} \rightarrow 50 \mu \mathrm{M} \rightarrow 100 \mu \mathrm{M}
$$

Figure 1. Proliferation analysis for roscovitine-treated A172 and G28 cell lines in medium containing 10\% FBS (A and B) and under starvation using only $0.125 \%$ FBS (C and D). Cells were cultured under serial concentrations of roscovitine and as untreated controls for up to $96 \mathrm{~h}$ and proliferation was measured by the xCELLigence real-time cell analyzer as described in 'Materials and methods'.

(QT00057575), cyclin E (QT00063511), p21 (QT00062090), p53 (QT00060235) and GAPDH (QT01192646) (all from Qiagen). RT-qPCR was performed on a CFX96 Real-Time PCR system (Bio-Rad).

Protein isolation and western blot analysis. Cells were trypsinized as described before, centrifuged for $12 \mathrm{~min}$ at $4^{\circ} \mathrm{C}$ and $1,000 \mathrm{rpm}$, resuspended and washed in $1 \mathrm{ml}$ PBS and pelleted at $1,000 \mathrm{rpm}$ for $12 \mathrm{~min}$. The pellet was resuspended in 80-200 $\mu \mathrm{l}$ Jie's Buffer and allowed to dissolve on ice for $30 \mathrm{~min}$ with intermittent vortexing. After centrifugation at $13,000 \mathrm{rpm}$ for $30 \mathrm{~min}$ the protein-enriched suspension was transferred into a new tube and stored at $-80^{\circ} \mathrm{C}$ until further processing.

Protein quantification was performed using the Pierce BCA Protein Assay kit (Thermo Scientific) as per the manufacturer's instructions. The readout was carried out on a SoftMax microplate reader using the Softmax Pro 3.11 software (Molecular Devices, Sunnyvale, USA). Gel electrophoresis was performed using a $30 \mu \mathrm{g}$ protein solution. Antibodies were incubated using the Snap i.d. protein detection system (Millipore, Billerica, MA, USA) according to the manufacturer's instructions. Chemiluminescence detection was performed with the Fusion-SL4 system and the Fusion-Capt software 15.15 by using the Pierce ${ }^{\mathrm{TM}}$ ECL Western Blotting Substrate (Thermo) and quantified using the Bio-1D package v.15.01 software (all from Vilber Lourmat, Eberhardzell, Germany). $\beta$-actin was used as the loading control. The antibodies used were: antiCdk2 (rabbit polyclonal, 1:300, cat no. ab6538) and anti-p21 (mouse monoclonal EA10, 1:100, ab16767; both from Abcam, Cambridge, UK), anti- $\beta$-actin (mouse monoclonal, clone AC-15, 1:3,000), and anti-mouse and anti-rabbit secondary antibodies (1:3,000, all from Sigma-Aldrich, St. Louis, USA).

Statistics. Statistic analysis and scientific graphing were performed using SPSS 20 (IBM software; Ehningen, Germany) and Prism 6 (GraphPad Software, Inc., La Jolla, CA, USA). The flow cytometric results were analyzed using the ANOVA test and corrected using the Dunnett's multiple comparison test for multiple comparisons. $\mathrm{P}<0.05$ was considered statistically significant.

\section{Results}

Proliferation analysis. The effects of roscovitine on proliferation were examined in A172 and G28 glioma cell lines.

Roscovitine induced a dose-dependent growth inhibition in A172 cells up to $50 \mu \mathrm{M}$ and a distinct reduction of cell viability at $100 \mu \mathrm{M}$ already after $24 \mathrm{~h}$ of treatment. $\mathrm{IC}_{50}$ at $72 \mathrm{~h}$ was $67.55 \mu \mathrm{M}$. G28 cells were less sensitive and cells proliferated in a similar manner as the untreated controls at concentrations of up to $50 \mu \mathrm{M}$. One hundred micromoles roscovitine exerted only a cytostatic effect, resulting in an $\mathrm{IC}_{50}$ of $2,127 \mu \mathrm{M}$ (Fig. 1).

When the same experiment was performed with FBSdeficient medium $(0.125 \% \mathrm{FBS}), \mathrm{IC}_{50}$ at $72 \mathrm{~h}$ was decreased to $9.12 \mu \mathrm{M}$ in the A172 cells and to $2.02 \mu \mathrm{M}$ in $\mathrm{G} 28$ cells. Under 
A

A172 $72 \mathrm{~h}$

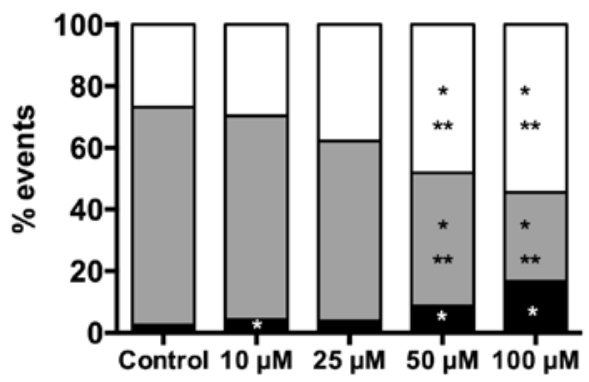

C

G28 $72 \mathrm{~h}$

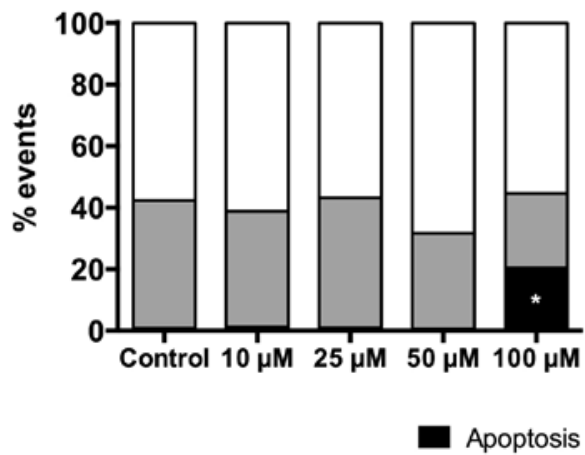

B

A172 $96 \mathrm{~h}$

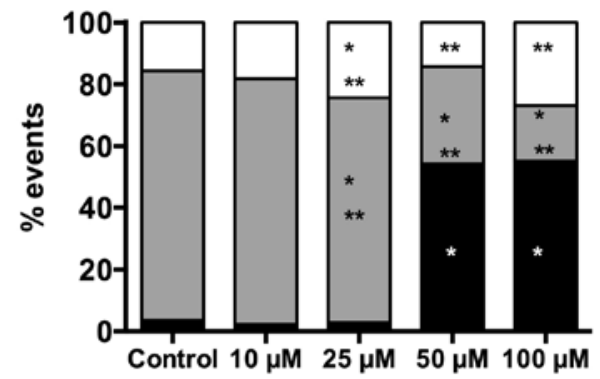

D

G28 $96 \mathrm{~h}$

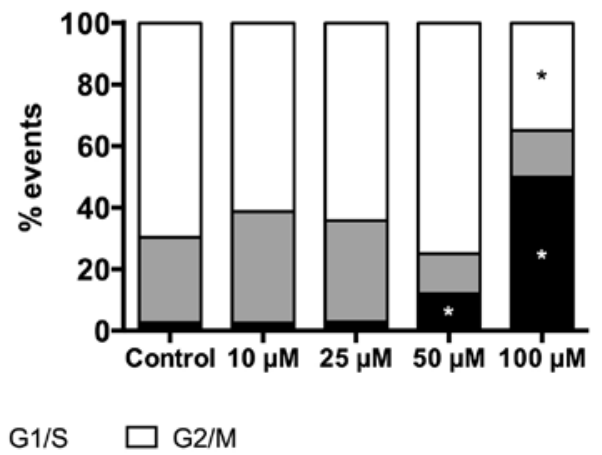

Figure 2. Cell cycle analysis by flow cytometry. The cell cycle distribution after treatment of A172 (A and B) and G28 cells (C and D) with increasing concentrations of roscovitine at 72 and $96 \mathrm{~h}$. Asterisks (") indicate the significant changes vs. the untreated controls $(\mathrm{P}<0.05)$. Double asterisks ( $\left.{ }^{* *}\right)$ indicate significant changes vs. the control cells in vital cells only (after removal of the apoptotic cells).

these conditions, there was an evident dose-dependent effect in G28 cells, in contrast to culturing with $10 \%$ FBS. Proliferation was similar under both conditions. The cells were monitored for up to $96 \mathrm{~h}$ to demonstrate continued proliferation even under nutrition-deficient conditions. The A172 cells reached a mean normalized cell index (CI) in the untreated controls of 4.4 after 96 h (vs. 3.6 when grown with $10 \%$ FBS). However, the G28 cells proliferated stronger with a mean CI after $96 \mathrm{~h}$ of 6.2 (vs. 2.5 when grown with $10 \%$ FBS). For comparable results with other studies on these cell lines, all subsequent experiments were performed using 10\% FBS.

Cell cycle analysis by flow cytometry. To determine by which mechanism roscovitine inhibited cell proliferation, we analyzed cell cycle distribution by flow cytometry. After $72 \mathrm{~h}$ incubation, there was a clear dose-dependent increase of the pre-G1 cell fraction in the A172 cells from $2.5 \%$ in the controls, to $4.4,3.9,8.7$ and $16.7 \%$ at $10,25,50$ and $100 \mu \mathrm{M}$, respectively (Fig. 2A). At the same time-point, there was an increase of the $\mathrm{G} 2 / \mathrm{M}$ fraction from 26.9 in the controls to $29.7,37.8,48.2$ and $54.5 \%$ at these concentrations. The G1/S percentage was reduced from 70.6 in the controls to $28.8 \%$ in cells treated with $100 \mu \mathrm{M}$ roscovitine. After $96 \mathrm{~h}$, the percentage of apoptotic cells reached 54.2 and $55.1 \%$ at 50 and $100 \mu \mathrm{M}$, respectively, vs. 3.6 in the untreated controls (Fig. 2B). The G1/S phase decreased from 80.8 in the controls to $17.9 \%$ at $100 \mu \mathrm{M}$ and at the same time the $\mathrm{G} 2 / \mathrm{M}$ percentage increased from 15.6 in the untreated controls to $26.9 \%$ at $100 \mu \mathrm{M}$.

In G28 cells, a significant increase of the apoptotic cell fraction was only observed at $100 \mu \mathrm{M}$ roscovitine at the $72 \mathrm{~h}$ time-point and levels ranged from $0.9 \%$ in the controls to 1.2 , $1.0,0.6$ and $20.5 \%$ at $10,25,50$ and $100 \mu \mathrm{M}$, respectively (Fig. 2C). However, the G1/S fraction decreased from 41.5 in the controls to $38.0,42.3,31.0$ and $24.1 \%$ at $10,25,50$ and $100 \mu \mathrm{M}$, respectively, and cells in the $\mathrm{G} 2 / \mathrm{M}$ phase amounted to 57.6 in the controls and 61.1, 56.7, 68.3 and 55.4\% at the same concentration range, respectively. A further increase of the apoptotic fraction was observed after 96-h incubation with roscovitine, reaching $12.1 \%$ already at $50 \mu \mathrm{M}$ and $49.9 \%$ at $100 \mu \mathrm{M}$ (vs. $2.6 \%$ in the controls). At this time-point, 50 and $100 \mu \mathrm{M}$ roscovitine further reduced G1/S cells to 12.9 and $15.2 \%$, respectively. The $\mathrm{G} 2 / \mathrm{M}$ cell fraction fluctuated at $61.2,64.2$ and $75.0 \%$ at 10,25 and $50 \mu \mathrm{M}$, and only at $100 \mu \mathrm{M}$ roscovitine was the level reduced to $34.9 \%$ (vs. 69.6 in the untreated controls).

Expression analysis of cell cycle regulator genes. A qPCR analysis for cell cycle regulators cyclins A, D and E, CDK2, CDK7, CDK9, p21 and p53 was performed in the two cell lines after 24, 48 and $72 \mathrm{~h}$ of treatment with roscovitine (Fig. 3). Under incubation with roscovitine at $10,25,50$ and $100 \mu \mathrm{M}$ for $72 \mathrm{~h}$, we measured dose- and time-dependent changes in all the genes investigated. In A172 cells, roscovitine induced the expression of CDK2 and cyclin D and suppressed p21, p53, CDK7, CDK9, cyclins A and E at $72 \mathrm{~h}$. At the growth-inhibiting concentrations of 10,25 and $50 \mu \mathrm{M}$, CDK2 expression was increased 1.1-, 1.3- and 1.5-fold, respectively. At $100 \mu \mathrm{M}$, the concentration leading to cell death, decreased to 0.3 -fold of the untreated controls. The expression of p21 was steadily induced over the dosing range, reaching a peak of 4.6-fold at 

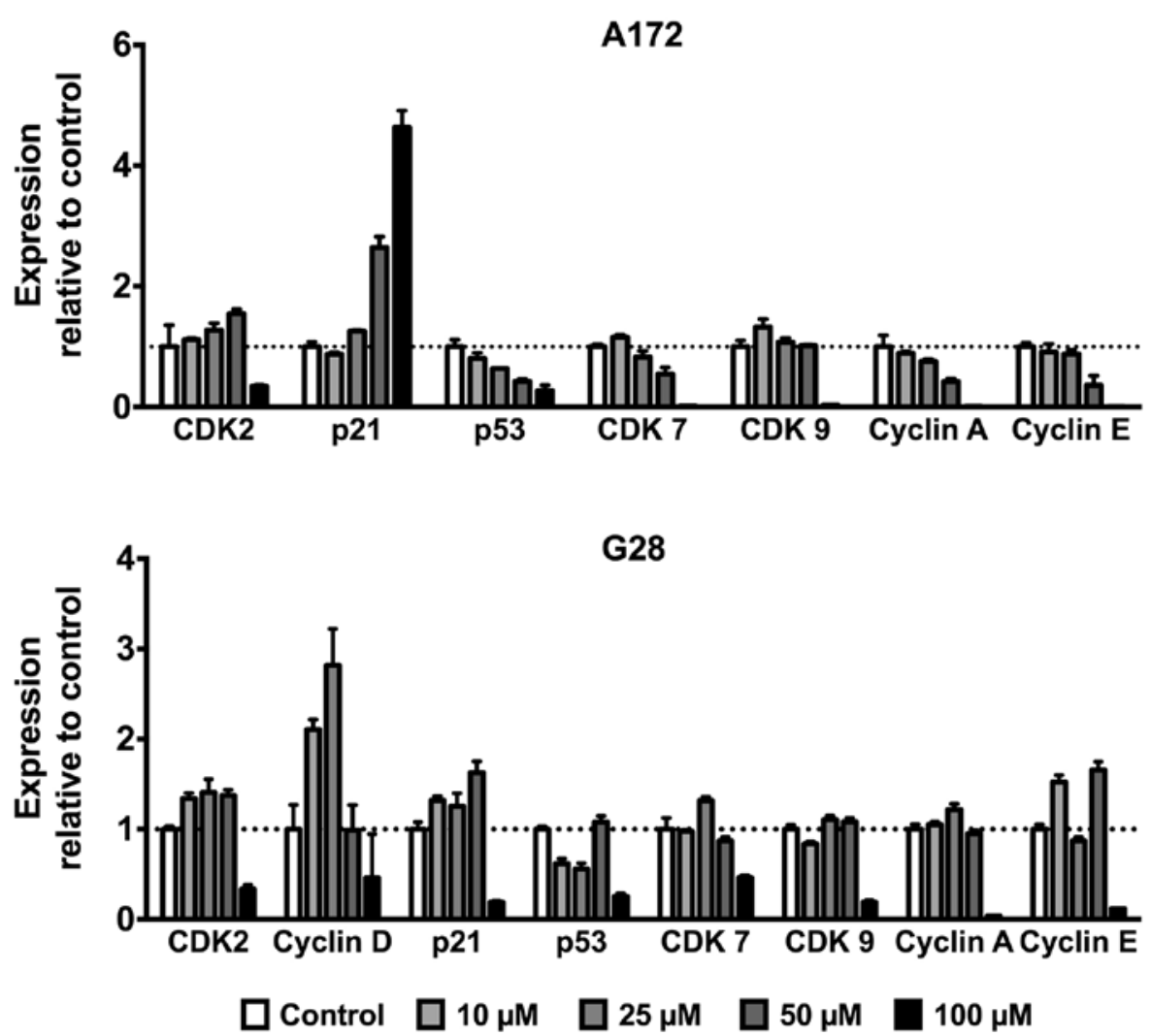

Figure 3. Relative gene expression in A172 and G28 cells treated with roscovitine at concentrations of 10-100 $\mu \mathrm{M}$. Gene expression was determined by qPCR and normalized against GAPDH and untreated controls.

A

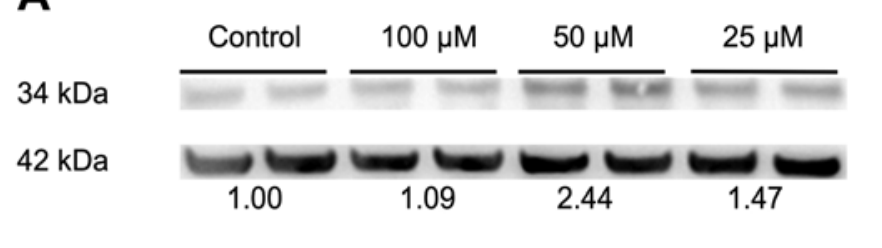

B

$18 \mathrm{kDa}$

$42 \mathrm{kDa}$

C

$34 \mathrm{kDa}$

$42 \mathrm{kDa}$

D

$18 \mathrm{kDa}$
A172 - 24h

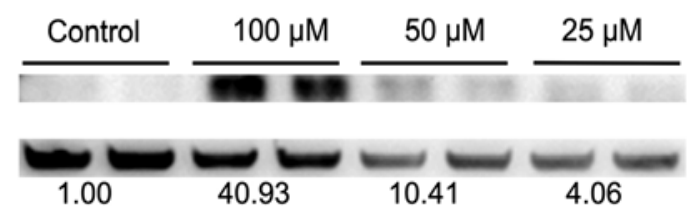

G $28-24 h$
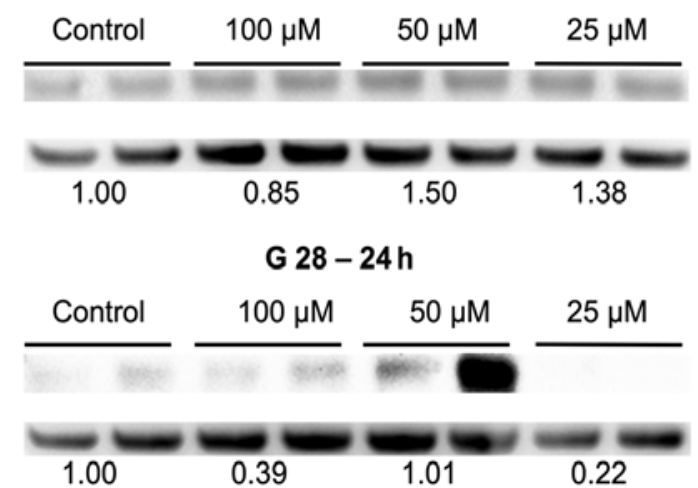

G $28-24 h$
CDK2

$\beta$-actin p21

$\beta$-actin

CDK2

$\beta$-actin

p21

$\beta$-actin

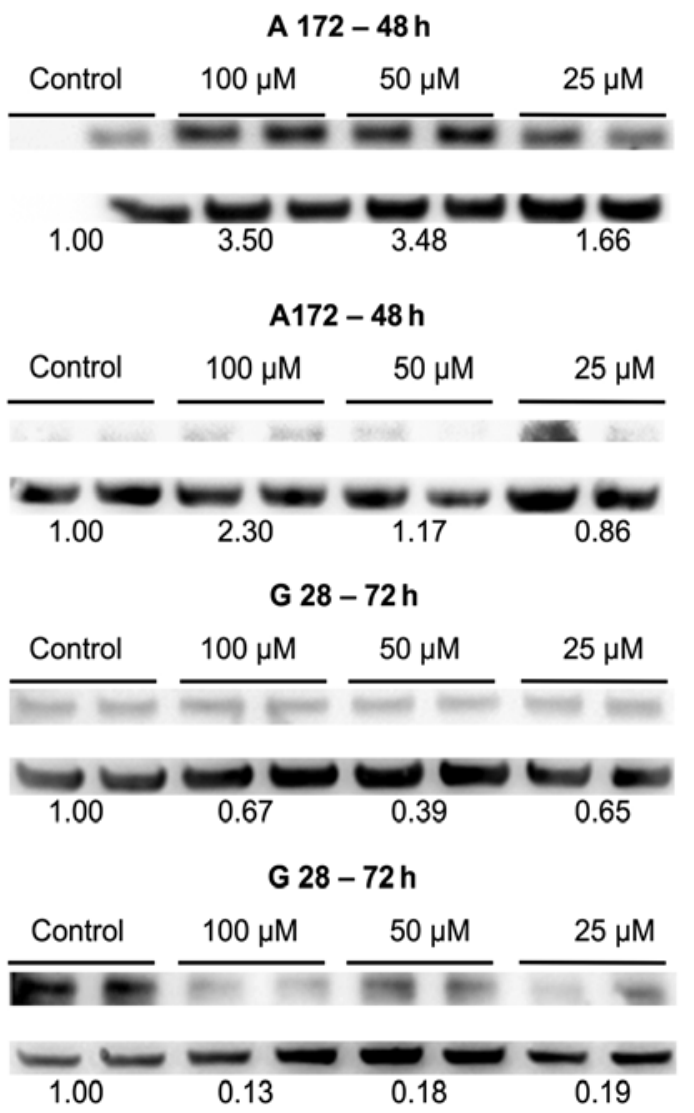

Figure 4. Western blot analysis of A172 and G28 cells treated with roscovitine. Panels show independent duplicate experiments of (A) CDK2 and (B) p21 expression in A172 and in G28 cells (C, CDK2; D, p21). Numbers show the densitometrically determined expression values after normalization to $\beta$-actin and the untreated controls. 
$100 \mu \mathrm{M}$ roscovitine vs. the untreated controls. The expression of p53, CDK7 and 9 and cyclins A and E was gradually suppressed with increasing roscovitine concentrations and at $100 \mu \mathrm{M}$ reached values of $0.3-, 0.02-, 0.04-$ and 0.01 -fold of the untreated controls, respectively. Cyclin D was not detected using qPCR in these cells.

In the less roscovitine-sensitive G28 cells, the gene expression patterns followed the trend identified in A172 cells, reaching expression levels of 0.3 for $\mathrm{p} 53,0.5$-fold for CDK7, 0.2-fold for CDK 9, 0.03-fold for cyclin A and 0.1-fold for cyclin E. CDK 2 also increased slightly and steadily at 10 , 25 and $50 \mu \mathrm{M}(1.3,1.4$ and 1.4-fold) and at $100 \mu \mathrm{M}$ showed similar decreases as identified in A172 cells (0.3-fold). In contrast to the A172 cells, G28 cells expressed cyclin D, which was induced by the lower roscovitine concentrations of 10 and $25 \mu \mathrm{M}$ (2.1- and 2.8-fold, respectively) and decreased at 50 and $100 \mu \mathrm{M}$ to $1.0-$ and 0.5 -fold, respectively. The expression of p21 was induced to 1.3-, 1.3- and 1.6-fold at 10, 25 and $50 \mu \mathrm{M}$ and decreased to 0.2 -fold at $100 \mu \mathrm{M}$. The clear dose-dependent effects observed in the proliferation and cell cycle analyses of the A172 cells were reflected in the gene expression and cell cycle studies, while the roscovitine effects of the G28 cells was less definite in all the analyses at 10\% FBS.

Analysis of CDK2 and 21 expression by western blot analysis. To confirm whether the expression changes observed at the mRNA level as a consequence of roscovitine treatment translate to the protein level, we analyzed the protein expression of CDK2 and p21 by western blot analysis. In the A172 cells, roscovitine treatment induced CDK2 expression already after $24 \mathrm{~h}$, with the strongest upregulation evident at $50 \mu \mathrm{M}$ (2.44-fold). At the longer incubation period of $48 \mathrm{~h}, \mathrm{CDK} 2$ was upregulated 3.50-fold at 50 and $100 \mu \mathrm{M}$ but only 1.66 -fold at $25 \mu \mathrm{M}$. The protein expression of $\mathrm{p} 21$ was strongly induced with increasing concentrations already after $24 \mathrm{~h}$ to values of 4.06-, 10.41- and 43.93-fold at 25, 50 and $100 \mu \mathrm{M}$, respectively. A less notable upregulation was observed after $48 \mathrm{~h}$ with values reaching $0.86-, 1.17$ - and 2.30 -fold of untreated controls for the same concentration range.

The concentration of $50 \mu \mathrm{M}$ appeared to be most efficient in upregulating CDK2 in G28 cells. After $24 \mathrm{~h}, \mathrm{CDK} 2$ was upregulated at the protein level to 1.50 -fold of the untreated controls and 25 and $100 \mu \mathrm{M}$ concentrations only resulted in values of 1.38- and 0.85-fold, respectively. In these cells, $72 \mathrm{~h}$ of incubation resulted in a suppression of CDK2 protein to $0.65-, 0.39$ - and 0.67 -fold at 25,50 and $100 \mu \mathrm{M}$, respectively. Levels of p21 at $24 \mathrm{~h}$ were reduced at 25 and $100 \mu \mathrm{M}$ in these cells (0.22- and 0.39 -fold, respectively) or were not altered at $50 \mu \mathrm{M}$ (1.01-fold). After the longer incubation of $72 \mathrm{~h}$, higher concentrations of roscovitine led to a strong downregulation of p21 to $0.19,-0.18$ - and 0.13 -fold at 25,50 and $100 \mu \mathrm{M}$. Of note, the two cell lines behaved in an opposite manner with respect to CDK2 and p21 expression, i.e., while A172 cells upregulated CDK2 and p21 when challenged with roscovitine, G28 cells suppressed the two proteins.

\section{Discussion}

GBM is the most common and most aggressive primary brain tumor in adults. Despite intensive therapeutic efforts, the prognosis remains poor (1). A successful multimodal therapy in this cancer needs to target multiple pathways, achieve sufficient concentration at the site of action within the brain and the treatment administered should have few side effects.

In the present study, we investigated the effect on the expression of CDK2, CDK7, CDK9 and cyclin A, D and E by using roscovitine in glioblastoma cells. We demonstrated that roscovitine induced cell cycle arrest in the G28 and A172 cell lines, which was paralleled by a decreased expression of CDK7, CDK9 and cyclin A, D and E. Furthermore, roscovitine induced apoptosis and decreased cell proliferation of the GBM cells.

Lim et al suggested that several modes of action can be postulated by the gene expression patterns observed after treatment with roscovitine. One of these modes of action leads to a reduced expression of CDK7, CDK 9 and cyclin D, the release inhibition of E2F and therefore suppression of E2F-dependent transcription, as well as suppression of the transcription by inhibiting RNA polymerase II-dependent transcription (29).

Previous findings have shown that cyclin E is often overexpressed in human tumors and the expression of the p21 and p27 inhibitors is often suppressed during tumor growth. This result demonstrates an involvement of CDK2 in human cancer (18). Other studies have shown that roscovitine induces cell cycle arrest by inhibiting CDK2 through competition for ATP-binding $(10,30)$. Our results show distinct expression patterns in the two investigated cell lines, suggesting that different modes of action may cause the cell cycle effects observed, i.e., while the CDK2 expression was suppressed only at the highest concentrations, we observed a clearer and dose-dependent effect for p21, p53, CDK7 and cyclin A. Our data suggest that the observed effects of roscovitine on proliferation and cell survival depend on the inhibition of various kinases, as shown by Bach et al (31). On the other hand, a potent inhibition of the CDK2/cyclin E complex by roscovitine has already been shown in clinical trials (32). Therefore, roscovitine affects more pathways simultaneously and its specific inhibition of CDKs is not its only effect.

Roscovitine also inhibits CDK7, forming an enzyme complex with cyclin $\mathrm{H}$. These data provide a direct connection between cell cycle regulation and transcription, CDK7 and cyclin $\mathrm{H}$ which form CAK, and a constituent of the basal transcription factor TFIIF, which phosphorylates serine residues within the heptapeptide repeat of the carboxyterminal domain (CTD) of RNA polymerase II (33).

Furthermore, roscovitine inhibits cyclin $\mathrm{H}$, cyclinD/CDK4 and cyclinD/CDK6 complexes by inhibiting CDK7 and reducing the cyclin $\mathrm{D}$ expression. This is due to the fact that CDK activation requires cyclin binding for conformational changes in the tertiary structure as well as phosphorylation at a conserved threonine residue. Cyclin binding leads to conformational changes in the tertiary structure of the CDKs, including the ATP-binding side, which allows subsequent phosphorylation that is required for complete CDK activation. Phosphorylation is catalyzed by the CAK $(34,35)$. CAK comprises a CDK7 complex with cyclin $\mathrm{H}$ and Mat1 (33). In quiescent cells and at the beginning of the G1 phase, E2F is controlled by pRB $(35,36)$. As soon as pRB is phosphorylated by cyclinD/CDK4 and cyclinD/CDK6 and subsequently by cyclinE/CDK2, E2F is released and transcription initi- 
ated $(35,37)$. Collectively, CDK2, CDK4, CDK6 and cyclin D are necessary for transcription. Most probably, roscovitine inhibits the activation of cyclinD/CDK4 and cyclinD/CDK6 by suppressing the expression of CDK7 and cyclin D, leading to inhibition of the transcription. Thus, E2F-dependent transcription of cycle relevant proteins, including cyclin $\mathrm{A}$ and $\mathrm{E}$, is suppressed, leading to cell cycle arrest at different stages. RNA-polymerase II performs the actual transcription. For activation it requires phosphorylation of its $\mathrm{C}$-terminal domain (CDT). CDK7/cyclinH/Mat1 CAK, which are components of the TFIIH complex, and CDK9/cyclinT (pTEFb) phosphorylate the CDT of RNA polymerase II (38). Thus, roscovitine may also inhibit transcription by impairing RNA-polymerase II activation.

Our results are not consistent with those of other studies which showed an increased mRNA expression of cyclin A, B, D $(32,39)$ and CDK7 and $9(26,39)$ in various types of cancer, but not glioma cells.

Similar to our gene expression results in the glioblastoma cell lines, Whittaker et al showed reduced cyclin A and D expression at the protein level by western blot analysis in human colon cancer cells (32). This decrease in phosphorylation may contribute to or even cause the decreased cyclin expression. This increased phosphorylation may most likely be due to an inhibition of CDK7 and 9 (32,39). Similar mechanisms likely caused the observed effects in the present study, although functional analyses to confirm these results were not performed.

Previous findings showed that roscovitine induced cell cycle arrest and concomitantly apoptosis in tumor cells of breast and colon cancer $(14,35)$ mostly due to mitochondrialmediated apoptosis activation of caspase-3, -8 (40) and -9 (34). Our results are in agreement with observations by WȩsierskaGądek et al $(26,30)$, showing that roscovitine induces G2/M-phase cell cycle arrest in tumor cells. In our study we observed progressive $\mathrm{G} 2 / \mathrm{M}$ arrest accompanied by decreasing G1/S fraction in A172 and G28 cell lines. The A172 cells showed a time- and concentration-dependent $\mathrm{G} 2 / \mathrm{M}$ arrest in almost all the samples, whereas G28 cells showed G2/M arrest after treatment with highest concentrations only. As the $\mathrm{G} 2 / \mathrm{M}$ phase is known as the most radio-sensitive phase in the cell cycle (41), roscovitine may be useful in combination with radiotherapy, which is also part of the current therapeutic standard for glioblastoma.

McClue et al (22) identified that the major effect of roscovitine is not by cell cycle arrest in a specific phase but rather an induction of apoptosis in different cell cycle phases. However, findings by those authors cannot be supported with the data of the present study.

Regarding our FACS results, we identified a concentrationand time-dependent induction of apoptosis with roscovitine treatment, accompanied by a decreased CDK 7 and 9 expression. Previous results have shown that roscovitine induces apoptosis by inhibiting RNA polymerase II-dependent transcription of the anti-apoptotic Bcl-2-family member Mcl-1 (myeloid cell leukemia 1) $(38,40)$. Those studies showed a decreased CDK7 and 9 expression due to roscovitine treatment with a consecutive decrease of RNA polymerase II phosphorylation leading to its depression. Using qPCR we determined a decreased expression of CDK7 and 9. Even in this tumor entity, roscovitine was capable of inducing apoptosis by disabling the
RNA polymerase II-dependent transcription of Mcl-1 due to a lack of CDK7 and 9 expression.

Previous studies reported a p53 increase in glioblastoma cells following roscovitine treatment $(16,26)$. There are p53-dependent and -independent pathways described in the literature $(10,16,18,26)$ with respect to apoptosis. However, there is a greater potency described against p53 wild-type cells than against mutant cells $(10,16,18,26)$. In the present study, the expression response of p53 under roscovitine incubation was different in the two cell lines. This is explained by the fact that one of the most important differences between the two cell lines is the p53 status. A172 cells bear wild-type p53, while a mutated p53 is present in the G28 gliosarcoma cell line $(42,43)$. It is likely that the stronger roscovitine influence identified in the A172 cells is likely due to the wild-type p53.

Previous findings have shown that roscovitine decreased the expression of p21 and p21 cleavage was involved in roscovitine induced apoptosis. Even in earlier studies on roscovitine it was presumed that a high expression of p21 inhibited the induction of apoptosis $(28,44-46)$. That finding is similar to our results for the G28 cells. The inhibition of p21 was time- and concentration-dependent. The investigation of A172 showed similar results until $48 \mathrm{~h}$. The expression of p21 after application of $100 \mu \mathrm{M}$ of roscovitine after $72 \mathrm{~h}$ was higher. This result can be interpreted as a regulatory mechanism to escape apoptosis.

In conclusion, our pilot study demonstrates an anti-proliferative and pro-apoptotic effect of roscovitine on two human glioblastoma cell lines in vitro, accompanied by distinct changes in gene expression of CDKs and cyclins, along with p53 and p21. Given the good oral bioavailability of roscovitine and its effect on the G2/M cell cycle phase, which is most sensitive to radiotherapy, this drug should be investigated in depth in further pre-clinical and clinical studies as it shows to be a promising agent against glioblastoma alone or in combination therapy $(24,47)$.

\section{References}

1. Maher EA, Furnari FB, Bachoo RM, Rowitch DH, Louis DN, Cavenee WK and DePinho RA: Malignant glioma: Genetics and biology of a grave matter. Genes Dev 15: 1311-1333, 2001.

2. Hengstschläger $M$, Hölzl $G$ and Hengstschläger-Ottnad $E$ : Different regulation of c-Myc- and E2F-1-induced apoptosis during the ongoing cell cycle. Oncogene 18: 843-848, 1999.

3. Schiffer D, Cavalla P, Migheli A, Chiò A, Giordana MT, Marino S and Attanasio A: Apoptosis and cell proliferation in human neuroepithelial tumors. Neurosci Lett 195: 81-84, 1995.

4. Costello JF, Plass C, Arap W, Chapman VM, Held WA, Berger MS, Su Huang HJ and Cavenee WK: Cyclin-dependent kinase 6 (CDK6) amplification in human gliomas identified using two-dimensional separation of genomic DNA. Cancer Res 57: 1250-1254, 1997.

5. Dirks PB, Hubbard SL, Murakami M and Rutka JT: Cyclin and cyclin-dependent kinase expression in human astrocytoma cell lines. J Neuropathol Exp Neurol 56: 291-300, 1997.

6. Olson JJ, Barnett D, Yang J, Assietti R, Cotsonis G and James CD: Gene amplification as a prognostic factor in primary brain tumors. Clin Cancer Res 4: 215-222, 1998.

7. Ono Y, Tamiya T, Ichikawa T, Kunishio K, Matsumoto K, Furuta T, Ohmoto T, Ueki K and Louis DN: Malignant astrocytomas with homozygous CDKN2/p16 gene deletions have higher Ki-67 proliferation indices. J Neuropathol Exp Neurol 55: 1026-1031, 1996.

8. Rollbrocker B, Waha A, Louis DN, Wiestler OD and von Deimling A: Amplification of the cyclin-dependent kinase 4 (CDK4) gene is associated with high cdk4 protein levels in glioblastoma multiforme. Acta Neuropathol 92: 70-74, 1996.

9. Srivenugopal KS and Ali-Osman F: Deletions and rearrangements inactivate the p16INK4 gene in human glioma cells. Oncogene 12: 2029-2034, 1996. 
10. Meijer L, Borgne A, Mulner O, Chong JP, Blow JJ, Inagaki N, Inagaki M, Delcros JG and Moulinoux JP: Biochemical and cellular effects of roscovitine, a potent and selective inhibitor of the cyclin-dependent kinases cdc2, cdk2 and cdk5. Eur J Biochem 243: 527-536, 1997.

11. Schutte B, Nieland L, van Engeland M, Henfling ME, Meijer L and Ramaekers FC: The effect of the cyclin-dependent kinase inhibitor olomoucine on cell cycle kinetics. Exp Cell Res 236 4-15, 1997.

12. Nair BC, Vallabhaneni S, Tekmal RR and Vadlamudi RK: Roscovitine confers tumor suppressive effect on therapy-resistant breast tumor cells. Breast Cancer Res 13: R80, 2011.

13. Pizarro JG, Folch J, Junyent F, Verdaguer E, Auladell C, Beas-Zarate C, Pallàs M and Camins A: Antiapoptotic effects of roscovitine on camptothecin-induced DNA damage in neuroblastoma cells. Apoptosis 16: 536-550, 2011.

14. Arısan ED, Coker A and Palavan-Ünsal N: Polyamine depletion enhances the roscovitine-induced apoptosis through the activation of mitochondria in HCT116 colon carcinoma cells. Amino Acids 42: 655-665, 2012.

15. Cho SJ, Kim YJ, Surh YJ, Kim BM and Lee SK: Ibulocydine is a novel prodrug Cdk inhibitor that effectively induces apoptosis in hepatocellular carcinoma cells. J Biol Chem 286: 19662-19671, 2011.

16. Liu NA, Jiang H, Ben-Shlomo A, Wawrowsky K, Fan XM, Lin S and Melmed S: Targeting zebrafish and murine pituitary corticotroph tumors with a cyclin-dependent kinase (CDK) inhibitor. Proc Natl Acad Sci USA 108: 8414-8419, 2011.

17. Coley HM, Safuwan NA, Chivers P, Papacharalbous E, Giannopoulos T, Butler-Manuel S, Madhuri K, Lovell DP and Crook T: The cyclin-dependent kinase inhibitor p57(Kip2) is epigenetically regulated in carboplatin resistance and results in collateral sensitivity to the CDK inhibitor seliciclib in ovarian cancer. Br J Cancer 106: 482-489, 2012

18. Malumbres $\mathrm{M}$ and Barbacid M: Cell cycle, CDKs and cancer: A changing paradigm. Nat Rev Cancer 9: 153-166, 2009.

19. Wellwood J and Taylor K: Central nervous system prophylaxis in haematological malignancies. Intern Med J 32: 252-258, 2002.

20. Sallam H, Jimenez P, Song H, Vita M, Cedazo-Minguez A and Hassan M: Age-dependent pharmacokinetics and effect of roscovitine on Cdk5 and Erk1/2 in the rat brain. Pharmacol Res 58: 32-37, 2008.

21. Yakisich JS, Sidén A, Idoyaga Vargas V, Eneroth P and Cruz M: Early inhibition of DNA synthesis in the developing rat cerebral cortex by the purine analogues olomoucine and roscovitine. Biochem Biophys Res Commun 243: 674-677, 1998.

22. McClue SJ and Stuart I: Metabolism of the trisubstituted purine cyclin-dependent kinase inhibitor seliciclib (R-roscovitine) in vitro and in vivo. Drug Metab Dispos 36: 561-570, 2008.

23. Dhavan R and Tsai LH: A decade of CDK5. Nat Rev Mol Cell Biol 2: 749-759, 2001.

24. Hassan M, Sallam H and Hassan Z: The role of pharmacokinetics and pharmacodynamics in early drug development with reference to the cyclin-dependent kinase (Cdk) inhibitor-roscovitine. Sultan Qaboos Univ Med J 11: 165-178, 2011.

25. Paprskárová M, Krystof V, Jorda R, Dzubák P, Hajdúch M, Wesierska-Gadek J and Strnad M: Functional p53 in cells contributes to the anticancer effect of the cyclin-dependent kinase inhibitor roscovitine. J Cell Biochem 107: 428-437, 2009.

26. Wesierska-Gadek J, Borza A, Komina $O$ and Maurer M: Impact of roscovitine, a selective CDK inhibitor, on cancer cells: Bi-functionality increases its therapeutic potential. Acta Biochim Pol 56: 495-501, 2009.

27. Alvi AJ, Austen B, Weston VJ, Fegan C, MacCallum D, Gianella-Borradori A, Lane DP, Hubank M, Powell JE, Wei W, et al: A novel CDK inhibitor, CYC202 (R-roscovitine), overcomes the defect in p53-dependent apoptosis in B-CLL by down-regulation of genes involved in transcription regulation and survival. Blood 105: 4484-4491, 2005.

28. Slovackova J, Smarda J and Smardova J: Roscovitine-induced apoptosis of H1299 cells depends on functional status of p53. Neoplasma 59: 606-612, 2012.
29. Lim YM, Yamasaki Y and Tsuda L: Ebi alleviates excessive growth signaling through multiple epigenetic functions in Drosophila. Genes Cells 18: 909-920, 2013.

30. Węsierska-Gądek J, Gritsch D, Zulehner N, Komina O and Maurer M: Roscovitine, a selective CDK inhibitor, reduces the basal and estrogen-induced phosphorylation of ER- $\alpha$ in human ER-positive breast cancer cells. J Cell Biochem 112: 761-772, 2011.

31. Bach S, Knockaert M, Reinhardt J, Lozach O, Schmitt S, Baratte B, Koken M, Coburn SP, Tang L, Jiang T, et al: Roscovitine targets, protein kinases and pyridoxal kinase. J Biol Chem 280: 31208-31219, 2005.

32. Whittaker SR, Walton MI, Garrett MD and Workman P: The cyclin-dependent kinase inhibitor CYC202 (R-roscovitine) inhibits retinoblastoma protein phosphorylation, causes loss of cyclin D1, and activates the mitogen-activated protein kinase pathway. Cancer Res 64: 262-272, 2004.

33. Bertoli C, Klier S, McGowan C, Wittenberg C and de Bruin RA: Chk1 inhibits E2F6 repressor function in response to replication stress to maintain cell-cycle transcription. Curr Biol 23: 1629-1637, 2013.

34. Fischer PM and Lane DP: Inhibitors of cyclin-dependent kinases as anti-cancer therapeutics. Curr Med Chem 7: 12131245,2000

35. Weinberg RA: The retinoblastoma protein and cell cycle control. Cell 81: 323-330, 1995.

36. Morgan DO: Principles of CDK regulation. Nature 374: 131-134, 1995.

37. MacCallum DE, Melville J, Frame S, Watt K, Anderson S, Gianella-Borradori A, Lane DP and Green SR: Seliciclib (CYC202, R-Roscovitine) induces cell death in multiple myeloma cells by inhibition of RNA polymerase II-dependent transcription and down-regulation of Mcl-1. Cancer Res 65: 5399-5407, 2005.

38. Erguven M, Bilir A, Yazihan N, Korkmaz S, Aktas E, Ovalioglu C, Dundar $\mathrm{T}$ and Seyithanoglu H: Imatinib mesylate decreases the cytotoxic effect of roscovitine on human glioblastoma cells in vitro and the role of midkine. Oncol Lett 3: 200-208, 2012.

39. Whittaker SR, Te Poele RH, Chan F, Linardopoulos S, Walton MI, Garrett MD and Workman P: The cyclin-dependent kinase inhibitor seliciclib (R-roscovitine; CYC202) decreases the expression of mitotic control genes and prevents entry into mitosis. Cell Cycle 6: 3114-3131, 2007.

40. Murphy ÁC, Weyhenmeyer B, Noonan J, Kilbride SM, Schimansky S, Loh KP, Kögel D, Letai AG, Prehn JH and Murphy BM: Modulation of Mcl-1 sensitizes glioblastoma to TRAIL-induced apoptosis. Apoptosis 19: 629-642, 2014.

41. Pawlik TM and Keyomarsi K: Role of cell cycle in mediating sensitivity to radiotherapy. Int J Radiat Oncol Biol Phys 59: 928-942, 2004

42. Sato Y, Kurose A, Ogawa A, Ogasawara K, Traganos F, Darzynkiewicz Z and Sawai T: Diversity of DNA damage response of astrocytes and glioblastoma cell lines with various p53 status to treatment with etoposide and temozolomide. Cancer Biol Ther 8: 452-457, 2009.

43. Akudugu J, Gäde G and Böhm L: Cytotoxicity of azadirachtin A in human glioblastoma cell lines. Life Sci 68: 1153-1160, 2001.

44. Zhang T, Jiang T, Zhang F, Li C, Zhou YA, Zhu YF and Li XF: Involvement of $\mathrm{p} 21^{\text {Waf } 1 / \text { Cipl }}$ cleavage during roscovitine-induced apoptosis in non-small cell lung cancer cells. Oncol Rep 23: 239-245, 2010.

45. Schmidt M and Fan Z: Protection against chemotherapy-induced cytotoxicity by cyclin-dependent kinase inhibitors (CKI) in CKI-responsive cells compared with CKI-unresponsive cells. Oncogene 20: 6164-6171, 2001.

46. Gartel AL and Tyner AL: The role of the cyclin-dependent kinase inhibitor p21 in apoptosis. Mol Cancer Ther 1: 639-649, 2002.

47. Neyns B, D'haeseleer M, Rogiers A, Van de Cauter J, Chaskis C, Michotte A and Strik H: The role of cytotoxic drugs in the treatment of central nervous system gliomas. Acta Neurol Belg 110: 1-14, 2010. 